\title{
Where Do Social Preferences Come From?
}

\author{
Chaning Jang ${ }^{\mathrm{a}}$, John Lynham ${ }^{\mathrm{b}, 1}$ \\ ${ }^{a}$ Department of Psychology, Princeton University \\ ${ }^{b}$ Department of Economics $\& 3$ UHERO, Saunders 542, 2424 Maile Way, University of Hawai'i at Mānoa, Honolulu, HI 96822
}

\begin{abstract}
Where do preferences for fairness come from? We use a unique field setting to test for a spillover of sharing norms from the workplace to a laboratory experiment. Fishermen working in teams receive random income shocks (catching fish) that they must regularly divide among themselves. We demonstrate a clear correlation between sharing norms in the field and sharing norms in the lab. Furthermore, the spillover effect is stronger for fishermen who have been exposed to a sharing norm for longer, suggesting that our findings are not driven by selection effects. Our results are consistent with the hypothesis that work environments shape social preferences.
\end{abstract}

Keywords: ultimatum game; social preferences; fairness; workplace spillovers

JEL Codes: Q2, C9, C7, B4, D1

\section{Introduction}

Human beings demonstrate strong social preferences for fair outcomes (Charness and Rabin 2002; Fehr and Gachter 2002, Fehr and Fischbacher 2003). This has puzzled many scholars in the social sciences, particularly when revealing a preference for an equitable outcome is at odds with individual profit maximization. Two strands of inquiry have emerged in an attempt to explain the origins of preferences for fairness. The first explores whether human beings are innately fair. Neurological, physiological, and genetic differences appear to explain some differences in preferences. Koenigs and Tranel (2007) show that patients with ventromedial prefrontal cortex damage reject a higher proportion of unfair ultimatum offers than those in comparison groups. Van den Bergh and Dewitte (2006) find that males with lower exposure to pre-natal androgen have a stronger preference for fairness. Burnham (2007) shows that men who reject low offers have significantly higher testosterone levels than those who accept. Wallace et al. (2007) provide evidence for genetic heritability playing a non-trivial role in ultimatum game behavior.

The second strand investigates whether social and cultural factors explain differences in preferences for fairness (Henrich 2000; Henrich et al. 2001, 2004, 2010). Researchers have conducted ultimatum games in

Email addresses: cjang@princeton.edu (Chaning Jang), lynham@hawaii.edu (John Lynham)

${ }^{1}$ Corresponding author 
different societies across the globe and found that differences in market integration and religious participation are positively correlated with fairness (Henrich et al. 2010). However, Oosterbeek et al. (2004) ran a metaanalysis of 37 studies and 75 ultimatum games to show that although regional differences do account for some of the variation in responder behavior, cultural markers have little influence on overall behavior. Although few would argue that behaviors are exactly consistent across location and culture, two problems naturally arise with cross-cultural studies. First, the scope of what we consider to be relevant for quantifying culture, let alone delineating characteristics that create uniqueness, are not well defined. Second, the literature is largely silent on the direction of causality: ${ }^{2}$ Simultaneous feedback between culture and norms is no less probable than uni-directional causality.

Although we have recently learnt a lot about factors that influence preferences for fairness, there are still large differences in preferences within genetically and culturally similar populations. Our research question in this paper is to test whether work environments influence individual preferences. We show that fishermen who are exposed to 50/50 sharing rules on a daily basis are significantly more likely to reject unequal splits in an ultimatum game than those working under 60/40 sharing norms. To account for potential selection bias, we demonstrate that this result is driven by experienced fishermen who have been exposed to the sharing norms for longer than their counterparts. Thus, we offer evidence in support of a third mechanism for understanding the origins of fairness: the institutions particular to an individual's work environment can have strong effects on preferences. In related work, Leibbrandt et al. (2013) compare competitiveness in traditional fishing societies where local natural forces determine whether fishermen work in isolation or in collectives. They present strong evidence that fishermen who fish individually are far more competitive than fishermen who fish in groups, and that this difference emerges with experience. This strongly suggests that social preferences are, in part, shaped by work environments and institutions.

\section{Background and Experimental Methodology}

Our population of interest is a small-scale fishing community on the eastern shores of Lake Victoria in Kenya. A single unpaved road connects the town of a few thousand people to the nearest major city. The dominant industry in this town is fishing, with both subsistence and commercial fishing taking place. Like other Kenyan fishing communities on Lake Victoria, the residents are predominantly Luo in ethnicity and Christian in religion. These fishermen are an ideal group for studying the effect of work environments on behavioral preferences, particularly using the ultimatum game. The small-scale fishermen receive random income shocks (their daily catch), and (since they typically work in teams) they often have to make decisions

2 Lambarraa and Riener (2015) and Shariff and Norenzayan (2007) prime religious culture or religion directly and show increases in charitable giving. It is unclear whether this establishes the effect of culture on behavior or the effect of religious institutional norms on behavior. 
about how to share joint income (McConnell and Price 2006). Thus sharing norms concerning income redistribution are reinforced daily.

In this community, most of the fishermen do not own their boat. Instead, they use boats belonging to land-based owners and share the proceeds from their catch as payment for use of the equipment. Fishermen are divided into two primary groups: night and day. The two groups target different species of fish. Night fishermen target Omena (Rastrineobola argentea). They fish using finely meshed seine nets around the edges of the lakes, near to the town. There are typically 3 to 4 people per boat. Perhaps because this type of fishing is a lot easier, fishermen have developed a sharing norm of splitting their catch 50/50 with the owner of the boat. Day fishermen target Mbuta (Lates niloticus). In contrast to night fishermen, they sail many miles into the lake and use larger mesh gill nets and long-lines with hooks. There are typically 2 to 3 people per boat. These fishermen split their catch 60/40 with boat owners (the owner receives $40 \%$ of the catch). Fishing is regulated by the local Beach Management Unit (BMU), a governing body that is authorized by the Kenyan government to provide and enforce rules to manage the beachfront and fishing grounds. Fishermen must be registered with the BMU in order to land on the beach and sell their fish. In practice, nearly all of the fishermen who fish in this community live their day-to-day lives here as well; existence of commuting fishing is rare.

Our experiment took place in cooperation with the BMU in the town meeting hall. For 4 days, we invited fishermen in the community to participate, with all efforts made to reach out to day and night fishermen alike. In all, 200 fishermen participated in the experiment. On average, they earned 381 Kenyan Shillings (approx. USD 4.50) for 2 hours of their time. Fishermen registered with some basic demographic information and were assigned a random ID number. To measure fairness, we employed the strategy method version of the ultimatum game. Fishermen were taken individually into a private room with a trained enumerator. Subjects were assigned as proposers or responders if their ID number was odd or even, respectively, with each subject participating in a single role. Both proposers and responders were introduced to the game, provided examples, and had to correctly answer comprehension questions before participating. Finally, proposers and responders were given blank index cards to write their respective offers and minimum acceptable offers (MAO), and then told to fold and place the cards into a sealed container while the enumerator waited outside. The stakes in this game were for real money, and the amount to be split was 100 Kenyan Shillings (close to one day's wages). To maintain full anonymity, participants were randomly paired among all participants upon conclusion of the experimental sessions. Payments were distributed in the two days following the experimental sessions and every single fishermen showed up to collect payment. 


\section{Results}

The outcomes of interest are offers and MAOs. Of the 200 participants, we have data from 99 proposers and 101 responders. Overall, offers and MAOs are in-line with other ultimatum games. Proposers tend to offer fair splits (the mode offer is 50), while responders reject unfair offers (see Table 1 for details). To study the effect of institutions on fairness norms, we use demographic data collected at registration which asks for the type of gear used by fishermen. As mentioned earlier, day and night fishermen use gear specific to their fishing purpose. We can then classify fishermen who report the use of seine nets as night fishermen and those who report gill nets or long-lines as day fishermen. We avoided asking fishermen directly if they are night or day fishermen to reduce potential priming of existing sharing norms.

Splitting our sample by day and night fishermen reveals interesting results. As shown in Table 2 , t-tests reveal no significant differences between proposals by day and night fishermen ( $p$-value 0.72). However, we find that night fishermen report significantly higher MAOs than day fishermen ( $p$-value 0.013). Thus, fishermen who operate under a 50/50 sharing norm require a larger offer than those who operate under a $60 / 40$ norm.

To target the causal direction of this relationship, we split the sample by whether the individual is a coxswain or not. Coxswains are more experienced (though not necessarily older) and skilled fishermen who lead their fishing crew. Coxswains are responsible for allocating the proceeds from the daily catch between the crew and the boat owner. Thus, it is reasonable to expect coxswains to have operated under, and be responsible for enforcing, their associated sharing norms for a longer amount of time than their less experienced peers. By splitting the sample into coxswains and non-coxswains, we see that differences in MAOs are indeed driven by the more experienced fishermen. Tables 3 and 4 show no significant differences in MAOs by non-coxswains ( $p$-value 0.461 ), while night coxswains require significantly higher offers than their day counterparts ( $p$-value 0.001).

Likewise, we see that within day and night fishermen, MAOs between coxswains and non-coxswains are significantly different. While non-coxswains in both groups have an average MAO of around 40, coxswain behavior deviates strongly in opposite directions. Day coxswains have MAOs significantly lower than noncoxswains ( $p$-value 0.021) (Table 5), whereas night coxswains have MAOs significantly higher than noncoxswains ( $p$-value 0.016) (Table 6). These results together lend evidence to the notion that fairness behavior arises causally through exposure to an individual's work environment. We see that fishermen from a small homogenous community exhibit differences in perceived fairness due to differences in workplace sharing norms, which are linked to the underlying ecology of the species they target.

What drives these differences in MAOs between night and day fishermen? One potential explanation is that responders place themselves in the position of a boat-owner when considering their MAO: fishermen receive the initial income (daily catch) and boat-owners then receive a share based on pre-established norms. 
Analogous to responders, the boat-owner has the power to reject an offer by restricting the future use of the boat. This may explain why day fishermen are willing to accept around 40 percent, just as their boat-owner counterparts do.

Why does this behavior manifest in MAOs and not in proposer offers? If fishermen view the proposer role as that of a fishermen, we might expect day fishermen to propose 40 percent for the responder. But responder identities are anonymous. A rational proposer should incorporate the beliefs of day and night fishermen into his strategy, and increase his offer to avoid rejection by night fishermen (as observed in the data). Responders don't need to incorporate group specific beliefs since they are not subject to the same strategic concerns.

\section{Conclusion}

Where does fairness come from? Scholars have investigated the cultural and biological origins of fairness and we supplement this research by exploring the role of institutional factors. We show that fishermen from a single culture have different notions of fairness that arise from profit sharing institutions related to their work environment. Fishermen accustomed to 50/50 splits are more likely to reject unequal splits than those accustomed to 60/40 sharing rules. Furthermore, we provide evidence that this result is not driven by selection. The fact that the result holds for experienced coxswains and not for their less experienced colleagues suggests that individuals who are exposed for longer periods to certain institutional norms absorb these rules into their preferences.

We are not the first to demonstrate feedbacks between work institutions and economic behavior. Carpenter and Seki (2005) and Burks et al. (2006) show that among fishermen and bicycle messengers, respectively, those who are exposed to more competitive work environments are less cooperative in experiments. Gneezy et al. (2014) show that fishermen who work in groups show higher levels of trust and coordination than fishermen who work solo. Leibbrandt et al. (2013) show that fishermen who fish individually are more competitive than fishermen who fish in groups. We add to this literature by widening the domain of economic behaviors that are influenced by institutional factors and by addressing selection effects in demonstrating that preferences (as measured in an experiment) are driven by the length of time fishermen have been exposed to a sharing norm. 
Table 1: Summary Statistics

\begin{tabular}{lccccc}
\hline \hline & & & & & \\
& Mean & S.D. & Min & Max & N \\
\hline Offer & 46.1 & 8.38 & 20 & 70 & 99 \\
MAO & 42.2 & 17.0 & 0.50 & 99 & 101 \\
\hline \hline
\end{tabular}

Table 2: Day vs. Night - All

\begin{tabular}{lccccc}
\hline \hline & & & & & \\
& Night & Day & Difference & S.E. & N \\
\hline Offer & 46.44 & 45.83 & 0.611 & 1.698 & 99 \\
MAO & 45.95 & 37.62 & $8.326^{* *}$ & 3.303 & 101 \\
\hline \hline
\end{tabular}

Table 3: Day vs. Night - Non-Coxswains

\begin{tabular}{lccccc}
\hline \hline & & & & & \\
& Night & Day & Difference & S.E. & N \\
\hline Offer & 45.71 & 44.81 & 0.907 & 2.727 & 47 \\
MAO & 39.17 & 41.80 & -2.633 & 3.544 & 49 \\
\hline \hline
\end{tabular}

Table 4: Day vs. Night - Coxswains

\begin{tabular}{lccccc}
\hline \hline & & & & & \\
& Night & Day & Difference & S.E. & N \\
\hline Offer & 47.08 & 46.79 & 0.298 & 2.121 & 52 \\
MAO & 51.19 & 32.64 & $18.55^{* * *}$ & 5.197 & 52 \\
\hline \hline
\end{tabular}

Table 5: Coxswain vs. Non-Coxswain - Day

\begin{tabular}{lccccc}
\hline \hline & & & & & \\
& Non-Cxsn & Cxsn & Difference & S.E. & N \\
\hline Offer & 44.81 & 46.79 & -1.978 & 2.626 & 54 \\
MAO & 41.80 & 32.64 & $9.157^{* *}$ & 3.824 & 46 \\
\hline \hline
\end{tabular}


Table 6: Coxswain vs. Non-Coxswain - Night

\begin{tabular}{lccccc}
\hline \hline & & & & & \\
& Non-Cxsn & Cxsn & Difference & S.E. & $\mathrm{N}$ \\
\hline Offer & 45.71 & 47.08 & -1.369 & 2.017 & 45 \\
MAO & 39.17 & 51.19 & $-12.03^{* *}$ & 4.840 & 55 \\
\hline \hline
\end{tabular}

\section{Acknowledgements}

We thank Leonard Akwany, Caroline Achieng and Ecofinder Kenya for research assistance. We are indebted to Colton Jang for his invaluable assistance in conducting some aspects of the field work, data management, and organization. This study was made possible by NSF grant GEO-1211972 Social-ecological complexity and adaptation in marine systems. All errors are our own.

\section{References}

Van den Bergh, B., Dewitte, S., 2006. Digit ratio (2d: 4d) moderates the impact of sexual cues on men's decisions in ultimatum games. Proceedings of the Royal Society B: Biological Sciences 273, 2091-2095.

Burks, S.V., Carpenter, J.P., Goette, L., 2006. Performance pay and the erosion of worker cooperation: Field experimental evidence. IZA Discussion Paper .

Burnham, T.C., 2007. High-testosterone men reject low ultimatum game offers. Proceedings of the Royal Society B: Biological Sciences 274, 2327-2330.

Carpenter, J.P., Seki, E., 2005. Competitive work environments and social preferences: field experimental evidence from a japanese fishing community. Contributions in Economic Analysis \& Policy 5.

Charness, G., Rabin, M., 2002. Understanding social preferences with simple tests. The Quarterly Journal of Economics 117, 817-869.

Fehr, E., Fischbacher, U., 2003. The nature of human altruism. Nature 425, 785-791.

Fehr, E., Gachter, S., 2002. Altruistic punishment in humans. Nature 415, 137-140.

Gneezy, U., Leibbrandt, A., List, J.A., 2014. Ode to the sea: Workplace organizations and norms of cooperation. The Economic Journal .

Henrich, J., 2000. Does culture matter in economic behavior? ultimatum game bargaining among the machiguenga of the peruvian amazon. The American Economic Review 90, 973-979. 
Henrich, J., Boyd, R., Bowles, S., Camerer, C., Fehr, E., Gintis, H., 2004. Foundations of human sociality: Economic experiments and ethnographic evidence from fifteen small-scale societies. Oxford University Press.

Henrich, J., Boyd, R., Bowles, S., Camerer, C., Fehr, E., Gintis, H., McElreath, R., 2001. In search of homo economicus: behavioral experiments in 15 small-scale societies. The American Economic Review $91,73-78$.

Henrich, J., Ensminger, J., McElreath, R., Barr, A., Barrett, C., Bolyanatz, A., Cardenas, J.C., Gurven, M., Gwako, E., Henrich, N., et al., 2010. Markets, religion, community size, and the evolution of fairness and punishment. science $327,1480-1484$.

Koenigs, M., Tranel, D., 2007. Irrational economic decision-making after ventromedial prefrontal damage: evidence from the ultimatum game. The Journal of neuroscience 27, 951-956.

Lambarraa, F., Riener, G., 2015. On the norms of charitable giving in islam: Two field experiments in morocco. Journal of Economic Behavior \& Organization .

Leibbrandt, A., Gneezy, U., List, J.A., 2013. Rise and fall of competitiveness in individualistic and collectivistic societies. Proceedings of the National Academy of Sciences 110, 9305-9308.

McConnell, K.E., Price, M., 2006. The lay system in commercial fisheries: Origin and implications. Journal of Environmental Economics and Management 51, 295-307.

Oosterbeek, H., Sloof, R., Van De Kuilen, G., 2004. Cultural differences in ultimatum game experiments: Evidence from a meta-analysis. Experimental Economics 7, 171-188.

Shariff, A.F., Norenzayan, A., 2007. God is watching you priming god concepts increases prosocial behavior in an anonymous economic game. Psychological Science 18, 803-809.

Wallace, B., Cesarini, D., Lichtenstein, P., Johannesson, M., 2007. Heritability of ultimatum game responder behavior. Proceedings of the National Academy of Sciences 104, 15631-15634. 
Graphical Abstract
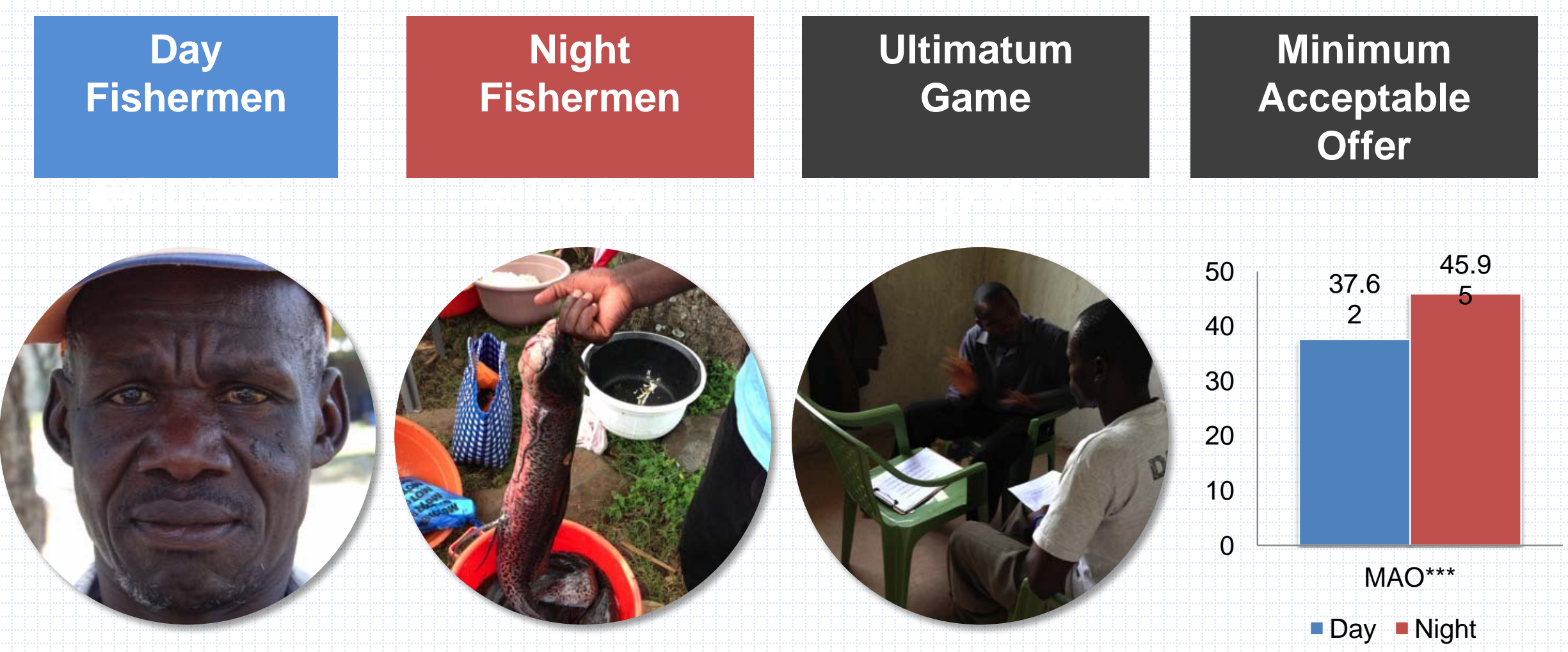